Case Report

\title{
A Case Report of Meilodosis
}

\section{Satheesh Kumar Bhandary ${ }^{1}$, Ivan Paraekulam Mani ${ }^{2}$, Rajeshwary Aroor ${ }^{3}$, Vadisha Bhat ${ }^{4}$ \\ ${ }^{1}$ Vice chancellor, Nitte (deemed to be University) \& Professor, ${ }^{2}$ Post Graduate Student, ${ }^{3}$ Professor \& Head, ${ }^{4}$ Professor, Department of ENT, KSHegde M edical Academy, M angalore.}

*Corresponding Author : Ivan Paraekulam M ani, Post Graduate Student, Department of ENT, KSHegde M edical Academy, M angalore.

Received

: 02.03.2018

Review Completed : 12.05.2018

Accepted

: 31.07.2018

Keywords : M eilodosis, neck abscess, cervical

lymphadenopathy

\begin{tabular}{|c|}
\hline Access this article online \\
\hline Quick Response Code \\
\hline \\
\end{tabular}

\begin{abstract}
Meilodosis is an infection caused by a gram negative bacterium, Burkholderia pseudomallei associated with high fatality rates. This organism is a widely distributed environmental saprophyte found in soil and stagnant water in the endemic regions of south East Asia and Australia. It was first diagnosed in Burma by Captain Alfred Whitmore, and his assistant, C.S. Krishnaswami in 1911. ${ }^{2}$ M eilodosis is an emerging pathogen in South India predominantly due to negligent management and a delayed diagnosis.

The majority of the cases of B. pseudomallei infections are subclinicalwith the primary modality of transmission being through broken skin. The disease predominantly manifests in individuals with diabetes mellitus, chronic renal disease and alcoholism. ${ }^{3}$ The majority of patients present with pyrexia and localized skin ulcerations or abscesses. ${ }^{4}$ There is a high incidence of pneumonia and septic shock following contamination. ${ }^{5}$ Transmission from a patient by droplet spread is rare even with the presence of pulmonary melioidosis. ${ }^{6}$ M eliodosis of the head and neck region is not common, however it accounts for $40 \%$ of the cases of supportive parotitis in children in Thailand and Cambodia. ${ }^{7}$ Diagnosis can be challenging due to its close symptomatic resemblance to tuberculosis. Isolation of the organism is difficult; this leads to poor identification of the causative agent and mismanagement.
\end{abstract}

\section{Case Report}

A 34 year old male who is a known case of type 2 diabetes on regular medication presented with history of mass on the left side of the neck for two weeks. Initially the patient complained of fever associated with chills in the first week which subsided following a five day antibiotic regime with Amoxicillin and clavulanic acid combination. The fever was superseded with a tender gradually progressive swelling measuring about $3 \times 2 \mathrm{~cm}$ on the left side of the neck. On examination the patient had a soft to firm fluctuant tender mobile swelling in the left level IV region of the neck with

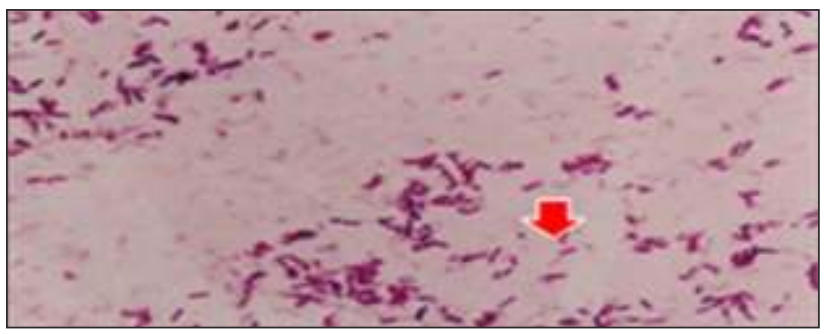

Fig 1 : The arrow showing gram negative B.Psudeomallei. The organism display a "safety pin" appearance on gram staining local rise of temperature. Blood investigations showed anelevated ESR and increased random blood sugar levels. An ultrasonography of the neck suggested multiple echoic lesions measuring $33 \times 16 \times 20 \mathrm{~mm}$ with small necrotic central areas. The impression of cervical lymphadenitis was suggested with fine needle aspiration cytology (FNAC) advised for correlation. The FNAC report was suggestive of supportive lymphadenitis. The patient underwent incision and drainage. The culture sensitivity of the pus was suggestive of burkholderia pseudomallei sensitive to ceftazidime. The patient responded well to the treatment.

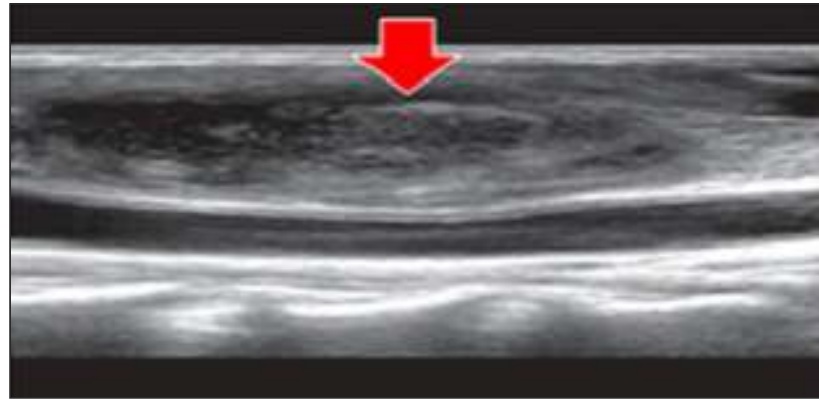

Fig 2 : Ultrasonography of the neck, displaying central necrosis with lymphadenopathy, Suggestive of tuberculosis 


\section{.Discussion}

Meliodosis is predominantly seen in diabetics and immunosuppressed patients. A population-based survey conducted in Udupi Karnataka India by Vandana KE et al ${ }^{8}$ to assess the serological evidence of exposure to $B$. pseudomallei in 711 adults aged 18 to 65 years illustrated that $29 \%$ of the study sample were seropositive. Another study conducted by Kang G etalin Vellur, Tamilnadu India near agricultural land reported a seropositivity of $10.2 \%$. The results of these studies are comparable to areas considered endemic, such as Vietnam (6.4-31.8\%) ${ }^{10}$, Thailand (21-47\%) ${ }^{11}$ and Australia. ${ }^{12}$

The presentation of Meliodosis with head and neck manifestations are rare. A clinical study conducted over a period of 6 years from 2005-2010 by K.Vidyalakshmi et al ${ }^{13}$ in India isolated a total of 14 out of the 95 cases with head and neck manifestations. These included 6 cases of cervical lymphadenopathies, 2 cases of parotid abscess and 6 dental abscess following manipulation.The rate of head and neck infections in South East Asia is higher with $40 \%$ of children evaluated for supportive parotid abscess being diagnosed with M eliodosis. ${ }^{7}$

Cervical lymphadenopathy is rare in Meliodosis. The clinical features mirror that of granulomatous diseases which could lead to the misdiagnosis of tuberculosis in

\section{References}

1. Dance DAB, Smith MD, Aucken HM, Pitt TL. Imported melioidosis in England and Wales. Lancet 1999; 353:208-9

2. John TJ, Jesudason M V, Lalitha M K, Ganesh A, M ohandas V, Cherian T et al. Melioidosis in India: the tip of the iceberg? Indian J Med Res 1996;103:62-5

3. Cheng AC, Currie BJ. M elioidosis: epidemiology, pathophysiology, and management. ClinM icrobiol Rev2005; 18:38-416Jesudason M

4. White NJ. M elioidosis. Lancet 2003;361:1715-22

5. Cheng AC, Currie BJ. M elioidosis: epidemiology, pathophysiology, and management. ClinM icrobiol Rev 2005; 18:383.

6. Currie BJ, Dance DA, Cheng AC. The global distribution of Burkholderia pseudomallei and melioidosis: an update. Trans R Soc Trop Med Hyg 2008; 102 Suppl 1:S1.

7. Chaowagul W, White NJ, Dance DA, et al. M elioidosis: a major cause of community-acquired septicemia in northeastern Thailand.J Infect Dis 1989; 159:890.

8. Currie BJ, Fisher DA, Howard DM, et al. The epidemiology of melioidosis in Australia and Papua New Guinea. Acta Trop 2000; $74: 121$.

9. Currie BJ, Fisher DA, Howard DM, et al. The epidemiology of melioidosis in Australia and Papua New Guinea. Acta Trop 2000; 74:121. endemic areas. ${ }^{14}$ The isolation of burkholderia pseudomallei is difficult unless the pathologist caries a high level of suspicion. Delayed specific treatment could lead to further complications. Fifty percent of patients who developed septic shock following Melioidosis in a study conducted by B.J. Currie et al died. ${ }^{6}$

The treatment protocol for Melioidosis includes an intensive 2 weeks of intravenous therapy with a sensitive antibiotic most commonly ceftazidime $(30-50 \mathrm{mg} / \mathrm{kg}$ IV q8hr; not to exceed $6 \mathrm{~g} /$ day) as a study conducted by White $\mathrm{NJ}$ et al observed. ${ }^{15}$ This should followed by a 3 month eradication therapy with oral combination of Trimethoprim and sulfamethoxazole. ${ }^{15,17,18}$

Due to a poor understanding of the nature of the disease recurrence rates followingan apparent cure are high in studies conducted in endemic areas with $16 \%$ of cases showing recurrence in Thailand ${ }^{19}$ and $6 \%$ in northern Australia. ${ }^{6}$

\section{Conclusion}

Burkholderia pseudomallei are bacterial infection poorly diagnosed or neglected due to a lack of awareness in India. With an incidence rate as high in India as endemic zones M eliodosis should be considered as a growing endemic in the region.

10. Leelarasamee A, Bovornkitti S. M elioidosis: review and update. Rev Infect Dis 1989; 11:413.

11. Kunakorn M, Jayanetra P, Tanphaichitra D. Man-to-man transmission of melioidosis. Lancet 1991; 337:1290.

12. Ralph A, McBride J, Currie BJ. Transmission of Burkholderia pseudomallei via breast milk in northern Australia. Pediatr Infect Dis J 2004; 23:1169.

13. Chaowagul W, White NJ, Dance DA, et al. M elioidosis: a major cause of community-acquired septicemia in northeastern Thailand. J Infect Dis 1989; 159:890.

14. Suputtamongkol Y, Chaowagul W, Chetchotisakd P, et al. Risk factors for melioidosis and bacteremicmelioidosis. Clin Infect Dis 1999; 29:408

15. Currie BJ, Jacups SP, Cheng AC, et al. M elioidosis epidemiology and risk factors from a prospective whole-population study in northern Australia. Trop M ed Int Health 2004; 9:1167.

16. Currie BJ, Ward L, Cheng AC. The epidemiology and clinical spectrum of melioidosis: 540 cases from the 20 year Darwin prospective study. PLoSNegl Trop Dis 2010; 4:e900.

17. McLeod C, Morris PS, Bauert PA, et al. Clinical presentation and medical management of melioidosis in children: a 24-year prospective study in the Northern Territory of Australia and review of the 
literature. Clin Infect Dis 2015; 60:21.

18. Dance DA, Davis TM, Wattanagoon Y, et al. Acute suppurativeparotitis caused by Pseudomonas pseudomallei in children. J Infect Dis 1989; 159:654.

19. Lumbiganon P, Viengnondha S. Clinical manifestations of melioidosis in children. Pediatr Infect DisJ 1995; 14:136

20. Gibney KB, Cheng AC, Currie BJ. Cutaneous melioidosis in the tropical top end of Australia: a prospective study and review of the literature.
Clin Infect Dis 2008; 47:603.

21. Limmathurotsakul D, Kanoksil M, Wuthiekanun V, et al. Activities of daily living associated with acquisition of melioidosis in northeast Thailand: a matched case-control study. PLoSNegl Trop Dis 2013; 7:e2072.

22. Jesudason MV, Anbarasu A, John TJ. Septicaemicmeliodosis in a tertiary care hospital in south India. Indian J Med Res 2003;117:119-21 